\title{
Dummy Hoy: Re-debating His Credentials for Nomination to the Hall of Fame
}

\section{Brian Malzkuhn}

\begin{abstract}
:
As a Deaf person looking up to Dummy Hoy as a professional sports inspiration, his exclusion from the baseball hall of fame had puzzled me for so long that I decided to investigate this mystery. By doing this, I had to put aside any personal bias, which is natural since deaf people, like many other minority groups, tend to overreach in ensuring the recognition of their own. I determined that I would argue his inclusion to the hall of fame based on his contributions to the game and compare his statistical achievements to these who played during Hoy's time.

A major factor that inspired me in becoming an advocate for his inclusion occurred in 2002 at Deaf Way 2, when there was a History through Deaf Eyes display at the Smithsonian Museum that showed different parts of deaf life such as the evolution of hearing devices, deaf schools, and deaf people through print and photo. The display made me realize that it was one of those moments where deaf history was shown through the "deaf eyes" and by citing historical information using the correct lens; I hope I would be able to justify his admission.
\end{abstract}

\section{Text}

\section{A Bit of History}

There is a tendency for deaf people's contributions to be overlooked by the mainstream society due to various reasons, which I will elaborate on later in this paper. There have been different findings that proved significant contributions by deaf people in different disciplines such as the role of deaf scientists in their fields as reported by Harry Lang of the National Technical Institution for the Deaf in Rochester, New York. Lang's work in uncovering historical facts added to the ever-growing deaf history corpus and hopefully this research on Hoy might further expand the collection.

Here is a bit of history before we begin to consider the beginning of Hoy's professional baseball career. Balls and strikes, along with various base running calls, were called by the umpires vocally. In addition to the calling, the umpires had to constantly shout out the "counts" throughout the game since electric scoreboards were not yet available. The only information at that time were manually operated scoreboards that kept track of runs scored and innings. To add some humor to this, it's a wonder that umpires still could utter sounds after the game!

Brief Biography of Dummy Hoy 
Dummy Hoy was born William Ellsworth Hoy on May 23, 1862 and passed away on December 15, 1961. He was born hearing and became deaf from spinal meningitis at age of 3 . He enrolled at the Ohio School for the Deaf in Columbus at age of 10 and graduated with honors and was a valedictorian for his class.

Photo credit: Danny Gabel

In School, Hoy learned shoe repair as a part of his vocational training and played baseball after school. To come to think of the possibility that he acquired the benefits of using hand signals while at the school playing amongst his deaf peers. After graduation, he opened a shoe repair shop and played baseball on weekends as his father insisted that Hoy focused on his trade as a shoe repairman rather pursuing a professional baseball career however Hoy's heart was set on playing baseball. Hoy was rather small at 5 feet 4 inches tall and weighing about 150 pounds but he was fast which became a staple of his longevity in the big leagues. His father eventually gave in and supported Hoy in his pursuit of his dream.

Dummy Hoy was confident with his skills, enough to turn down the first offer play for $\$ 60$ a month. He eventually went to play for an Oshkosh, Wisconsin team for $\$ 85$ a month in 1886 . In just two years, he moved up to the major league level with the Washington Nationals and at that level he played for four different teams spanning fourteen years.

\section{A Hit for Hoy}

At the beginning of Hoy's career he struggled with the game of baseball not because his skills were lacking but because he was having difficulty understanding what calls the umpires were making. To temporarily remedy this problem, Hoy had his third base coach interpret the balls and strikes signals but it eventually did not work out too well. Given Hoy's educational background attending the Ohio School for the Deaf in Columbus where he picked up the game of baseball, it would be safe to assume that there was a mechanism that deaf players used to signify certain calls. Being equipped with an understanding of how certain baseball calls should be signed, Hoy met with an umpire to discuss the idea of using hand signals- with the right hand to signify strikes and the left hand to represent balls, and additional gestures to display whether the player is out or safe.

The purpose of this is to give Hoy an equal footing in the game and the concept were embraced by the players and the fans and became a lasting part of the sport's history.

\section{Recognition for Hoy}

Thanks to Hoy's contribution, baseball gained hand signals that we enjoy seeing in baseball today! According to several evidences that I presented it can be shown that by giving credit to hearing people, due or undue, deaf people were effectively suppressed from being afforded some credit for their contributions. It is my hope by showing Hoy's impact on the game of baseball it would open people's eyes to other possibilities that could be realized as influence from or through deaf people. Unfortunately, it is not the case at this time as credit for the hand signals went to somebody else, a hearing umpire.

Bill Klem, An Umpire, National League, 1905 - 1951 
It is unfortunate as we can see on William J. Klem's Baseball National Hall of Fame plague it was written “... CREDITED WITH INTRODUCING ARM SIGNALS INDICATING STRIKES AND FAIR OR FOUL BALLS.” In 1888, well before Klem's career as an umpire began, Deaf Life mentioned Hoy's use of hand signals during the game. A 1891 drawing in St. Louis Globe Democrat depicts Hoy using signals providing further another evidence that Hoy introduced and used the hand signals. Despite this, the credit has been given to Klem. This happened is unknown to me at this time.

Comparing Hoy With Other Players He Played Against

Hoy played as a centerfielder from 1888 to 1902 for several teams. Hugh Duffy and Billy Hamilton, also centerfielders, played during Hoy's time and were elected into National Baseball Hall of Fame as oldtimers. A centerfielder - an important defensive position in the outfield - is noted for great speed to cover large parts of the field, from the left to the right, and usually possess a great arm to throw out any potential runners on base, especially the homeplate. Basically, the centerfielder serves as a defensive captain of the outfield.

Let's discuss statistics among these three players. Here is a chart of comparisons of statistics in different categories for you to view:

\begin{tabular}{|l|l|l|l|}
\hline Categories & Hugh Duffy & Billy Hamilton & Dummy Hoy \\
\hline Games & 1722 & 1578 & 1798 \\
\hline At Bats & 6999 & 6262 & 7123 \\
\hline Runs & 1545 & 1690 & 1426 \\
\hline Hits & 2397 & 2157 & 2954 \\
\hline RBI & 1299 & 736 & 726 \\
\hline Batting Avg. & .330 & .344 & .288 \\
\hline Slugging Avg. & .451 & .428 & .374 \\
\hline Doubles & 310 & 225 & 248 \\
\hline Triples & 117 & 94 & 121 \\
\hline Home Runs & 106 & 40 & 40 \\
\hline Total Bases & 3065 & 2690 & 2664 \\
\hline Stolen Bases & 599 & 937 & 597 \\
\hline Walks & 662 & 1187 & 1004 \\
\hline
\end{tabular}

When you look at the statistics you will be able to see that Hoy held his own as compared to the Hall of Famers. Only two statistics Hoy was weaker in were batting average and slugging percentage. Batting average displays the ability to collect base hits while slugging percentage measures the power of the hitter through his accumulation of total bases. Hamilton and Hoy were leadoff hitters, which can be attributed to their speed, while Duffy was a middle of the order hitter as his power and runner batted in (RBI) numbers indicated.

I want you to take a note of what was etched on Hugh Duffy's Hall of Fame plague which said "Brilliant as a Defensive Outfielder". That brought me to consider how well Hoy played defense. After some investigating, I discovered that Hoy was more than brilliant as he still is the current record holder for 
number of outs he threw to the home-plate from the outfield in a single game (three). Even more astounding is the fact that Hoy played without a glove during his time and as an outfielder he had to catch flyballs with his hare hands and throw the ball home without using cutoffs players to relay the throw which is a common practice nowadays. To add to this humor- the catcher at the home-plate had to catch the ball barehanded as well. The catcher who had to catch Hoy's throws was teammate Connie Mack, a Hall of Famer who, after his playing days, owned and managed Philadelphia A's for 50 years! Having witnessed Hoy's superb play defensively and offensively, Mack at one time proclaimed that Hoy belonged in the Hall of the Fame, a sentiment that was shared by others such as Clark Griffith a renowned old timer. The picture below shows Mack and Griffith conversing with Hoy in sign language forty-plus years ago.

Clark Griffith, Dummy Hoy (center), and Connie Mack at an All Star Game, 1939 Photo credit: Steve Sandy

In a nutshell, Hoy and Duffy were defense stalwarts! Here is a list of feats accomplished by Hoy:

- In 1888, during his rookie year, He led the National League with eighty-two Stolen Bases.

- He was the second player to hit a home run - grand slam —in American League History vs. Detroit Tigers in 5 th inning

- He lived until 99 years old, being the oldest living player at that time.

- He faced another deaf player: Luther "Dummy" Taylor of the NY Giants in 1902 which he went 2 for 4 against. It was the only time a deaf pitcher pitched against a deaf hitter in major league baseball history!

Adding His Rich Credentials to the Argument

Dummy Hoy has been recognized by the following organizations:

-Athletic Association of the Deaf Hall of Fame in 1951 (the first person ever elected)

- Ohio School for the Deaf Hall of Fame

- State of Ohio Hall of Fame

- Cincinnati Reds' Hall of Fame in 2003

- Gallaudet University named its baseball field, "Hoy Field" in 2001

However, he has yet to be recognized by National Baseball Hall of Fame often recognizes players for their contributions to the game which is not limited to just statistics. As we can see today with the hand signals being the integral part of how we would imagine the game of baseball, it was Hoy's contribution that allows everybody to enjoy these visual cues. This contribution alone, statistics withstanding, should be enough for the Hall of Fame to recognize him and grant him admission as there are two upcoming opportunities for Hoy to be elected into National Baseball Hall of Fame:

In 2012 as a pioneer in baseball: Hoy could be one as he was the catalyst in bringing hand signals to baseball; or 
In 2014 as an old-timer: Hoy could be because he was an extraordinary ball player with statistics comparatively with two other Hall of Famers who played during Hoy's time plus his defense not to taken lightly.

\section{Final Throw}

In 1961, I was watching the World Series between the New York Yankees and the Cincinnati Redlegs on TV and unknown to me was an appearance by Hoy to throw the first ceremonial pitch to begin the homestead in Cincinnati. It was quite an honor given the tradition of choosing political or celebrity figures to do the honor. The picture below shows Hoy throwing the first pitch from the stands as he was 99 years old at that time. Just two months later Hoy passed away, 7 months short of 100 years old!

Throughout his life, Dummy Hoy contributed to the world of baseball both as skilled player and also by introducing the now standard hand signals used by umpires. His exclusion from the National Baseball Hall of Fame is an unjust oversight, one that will hopefully be rectified in the future. 


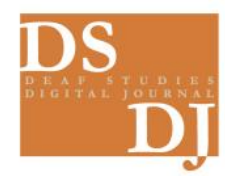

\section{Acknowledgements:}

Photos generously supplied by Danny Gabel, Steve Sandy, and Gallaudet Archives. English editing was done with help from Matthew Malzkuhn and Michelle Ktejik.

\section{References}

Craig, J. (2009) Retrieved May 2010 from http://cincinnati.com/blogs/ politics/ 2009/09/30/eyes-on reds-dummy-hoy

Gould, Stephen Jay. (2003) Triumph and Tragedy in Mudville, "The Amazing Dummy". W.W.Norton, New York: W.W. Norton.

Moore, Matthew S. and Dr. Robert F. Panara. (1999) Great Deaf Americans, 2nd Edition. Eden Prairie, MN: Deaf Life Press.

Sandy, S. and R. Miller. "No Dummy: William Ellsworth Hoy." Timeline, March-April 2000, pp. 4853.

Unknown. “The Colorful Legacy of ‘Dummy’ Hoy” Deaf Life Vol 5-6, November and December, 1992.

Veditz, G., et al. (1997) The Preservation of American Sign Language. Burtonsville, MD: Sign Media Inc. 